\title{
COMPARISON OF BIOCHEMICAL AND PHYSIOLOGICAL PROPERTIES OF NIGERIAN TOMATO FRUITS RIPENED UNDER DIFFERENT CONDITIONS
}

Abdul-Hammed $\mathrm{M}^{1}$, Bello $\mathrm{IA}^{1}$ and AA Olajire ${ }^{2}$

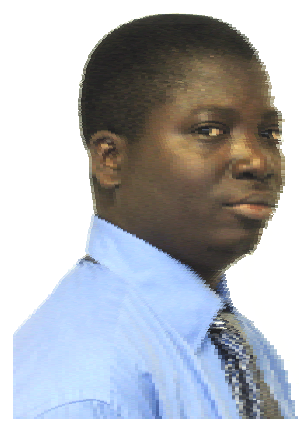

Misbaudeen Abdul-Hammed

*Corresponding author email: misbaulhameed@yahoo.co.uk

${ }^{1}$ Biophysical and Physical Chemistry unit, Department of Pure and Applied Chemistry, Ladoke Akintola University of Technology, Ogbomoso, Nigeria

${ }^{2}$ Environmental and Industrial Chemistry unit, Department of Pure and Applied Chemistry, Ladoke Akintola University of Technology, Ogbomoso, Nigeria 


\section{ABSTRACT}

The growth in chronic diseases such as obesity, diabetes, various types of cancers and cardiovascular diseases is an argument in favour of promoting fruit and vegetable consumption in Africa, with the main obstacle being the purchasing power. The objective of this study was to investigate the respective impacts of ripening stages and techniques of ripening on tomato fruit quality in order to recommend which of the conditions of ripening is better for optimum benefit of the tomatoes. The physiological and biochemical changes in tomato fruits of two varieties (Ibadan-Local and Roma cultivars) ripened using two different techniques (field and ambient temperature ripening) were monitored; the differences in the mean values between the ripening methods are discussed at appropriate significance levels. The mean differences in percent total solids for tomato fruits between the two conditions of ripening are significant $(\mathrm{P}<0.05$ at the breaker stage of Ibadan-local cultivar and $\mathrm{P}<0.01$ for other stages in the two varieties). The differences are much higher at the pink to fully-red stages in tomatoes ripened under the ambient temperature. Except at light-red stage of Ibadan-local cultivar and breaker stage of Roma cultivar, the mean differences in $\mathrm{pH}$ values between the ripening methods are significant $(\mathrm{P}<0.05$ at the breaker stage of Ibadan-local cultivar and at the light-red stage of Roma cultivar and $\mathrm{P}<0.01$ for other stages in the two varieties). Mean differences in percent titratable acidity (as citric acid) of the fruits under the two methods of ripening are also significant $(\mathrm{P}<0.05$ at the breaker stage of Roma cultivar and $\mathrm{P}<0.01$ for other stages in the two varieties) with exceptions at fully-red stage of the two varieties. However, high significant differences $(\mathrm{P}<0.01)$ exist between the mean values of reducing sugar, lycopene (but $\mathrm{P}<0.05$ at breaker stage of Roma cultivars) and beta-carotene contents of the tomato fruits under the two conditions of ripening, with higher values obtained mostly in the field ripening method. About $69.2 \mathrm{~g}$ and $58.3 \mathrm{~g}$ of tomato fruits, ripened on the parent plants (field ripening), at light-red stage of Ibadan-local and Roma-type respectively, are recommended daily in accordance with average daily recommendation of $25.2 \mathrm{mg}$ of lycopene per day in Canadian diet and from the study from Harvard School of Medicine. Equivalent quantities could only be reached by consuming higher quantities of tomatoes ripened at ambient temperature.

Key words: Ripening, tomato, cancer, beta-carotene, lycopene 


\section{INTRODUCTION}

Tomato, believed to have originated from Mexico where it is referred to as tomati, is one of the most widely grown and economically important vegetable crops all over the world including south-western and northern parts of Nigeria. Tomato can be eaten raw or cooked and is often processed to make tomato paste, sauce or juice, and is rich in potassium, vitamin $\mathrm{C}$, pro-vitamin $\mathrm{A}$ and some other mineral nutrients required for normal body metabolism.

The conversion of a tomato fruit from the mature green stage to fully ripened stage involves dramatic changes in colour, composition, aroma, flavour and texture. Ripening used to be thought of simply as resulting from a series of degradative processes involving senescence and probably because some of the more obvious changes require the action of hydrolytic enzymes, but it is now clear that ripening is dependent on a wide range of separate synthetic as well as degradative reaction [1]. The changes (highly coordinated) occur in the majority of the cells of the fruit and involve every sub-cellular compartment. Such various facets of ripening appear to be coordinated and regulated by plant hormones but may be modified by genetic and environmental factors $[2,3]$.

The production of the normal red colour of ripe fruit is due to the destruction of chlorophyll and the extensive accumulation of the carotenoids (lycopene and $\beta$ carotene) while the chloroplasts are transformed into chromoplasts [4].

Carotenoids, secondary metabolites, which are involved in vision of animals and Vitamin A (retinol) produced in-vivo from $\beta$-carotene, are essential precursors for normal growth and vision. They also, together with protein-carotenoid complexes, produce the pigmentation of many flowers and fruits. Lycopene, a major carotenoid without pro-vitamin A activity present in red tomatoes, is considered to be responsible for the beneficial effects of tomato fruits in relation to its abilities to act as a powerful antioxidant thus ameliorating the incidences of cardiovascular disease, cancer, diabetes, osteoporosis and even male infertility $[5,6,7,8]$.

Oxidative stress induced by reactive oxygen species is one of the focuses of recent research related to cancer and cardiovascular disease [9]. Reactive oxygen species react with cellular components, causing oxidative damage to such critical cellular biomolecules as lipids, proteins and DNA. This is strong evidence that this damage may play a significant role in the causation of several chronic diseases [10]. Such reactive oxygen species could be scavenged by the dietary intake of lycopene, $\beta$ carotene, tocopherol and vitamin $\mathrm{C}$, thereby reducing the risk of such chronic diseases, with lycopene having the highest quenching ability (twice as high as that of $\beta$-carotene and ten times higher than that of $\alpha$-tocopherol) [11].

Quality of the tomato fruits is determined by all the characteristics and attributes associated with satisfying the demands, needs and expectations of the person making the judgment [1]. Harvesting tomato fruits at mature- green stage is a worldwide 
practice, which is also practised in Nigeria due to the belief that tomatoes harvested at the mature- green stage make up the bulk of the commercial fresh market tomato crop because they tolerate rough handling better than the riper stages and hold the longest in storage, shipping, and on the supermarket shelf. In the industry, this is referred to as having a low shrinkage rate. Poverty level among Nigerians and other average Africans, coupled with galloping increase in the prices of foodstuff and nonawareness of the health benefits of tomato fruits, had assumed an alarming state. This has led to the preference to the quantity of purchased tomatoes rather than quality, thus posing environmental and health problems on average Nigerians.

The objective of the present study was to examine and elucidate the physiological and biochemical changes in tomato fruits composition during ripening in the field and at the ambient temperature using two tomato cultivars (Ibadan-local and Roma cultivars) grown in the southwestern and northern parts of Nigeria, respectively. The significant differences between tomatoes ripened under the two different techniques are also analyzed.

\section{MATERIALS AND METHODS}

\section{Fruit Sampling}

Tomato seeds (Lycopersicon esculentum, cultivars Ibadan Local and Roma) were collected from National Horticultural Institute (NIHORT), Ibadan- Oyo State, Nigeria They were grown during three separate similar farming seasons and harvested at various ripening stages according to colour index as previously described $[12,13]$. Preliminary analyses were carried out on the fruits variability, by picking $10-25$ tomato fruits belonging to the same ripening class and analyzing for the parameters in each fruit. A correlation coefficient of $r>0.88$ was obtained overall.

\section{Sample Preparation}

For field ripening, about 10-15 tomato fruits belonging to the same group were picked at random with respect to the targeted ripening stage every morning of the period of study. For ripening at ambient temperature, the tomato fruits were picked at once on reaching the mature green stage (in line with common practices) and were left to "selfripen" in a well-ventilated laboratory. In both methods of ripening, the fruits were packed in nylon bags and taken into the laboratory, where they were rinsed in some doubly distilled water and left to drain for some minutes. Individual tomatoes were sliced and all parts of the fruits utilized. The fruit tissue was cut into approximately 1.4 $-2.6 \mathrm{~cm}$ cubes and then homogenized.

\section{Extraction and Estimation of Lycopene and $\beta$-carotene}

Lycopene and $\beta$-carotene from the tomato fruits were extracted with hexane, methanol and acetone $(2: 1: 1)$ containing $2.5 \%$ BHT. The extract was treated with doubly distilled water, methanol and $20 \% \mathrm{KOH} /$ methanol $(1: 1: 1)$ to saponify any triglyceride present. The extract was washed with doubly distilled water and redissolved in hexane. The concentrations of lycopene and $\beta$-carotene in the hexane extract were determined spectrophotometrically against a hexane blank at $505 \mathrm{~nm}$ and

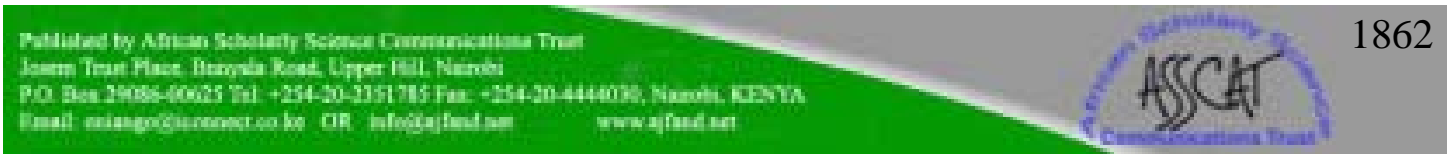


487 nm, respectively, using CECIL CE 3041 Spectrophotometer (Buck Scientific, USA).

\section{Estimation of other parameters}

The $\mathrm{pH}$ of the tomato aqueous extract was measured using $\mathrm{pH}$ meter Mettler Toledo-MP 120 (ThermoFisher Scientific Inc. Germany), the reducing sugar concentration was determined by the use of CECIL CE 3041 Spectrophotometer (Buck Scientific, USA), \% titratable acidity (as citric acid) and percent (\%) total solid were determined as previously described [14]. The experiments were repeated five times using separate but similar fruit samples.

\section{DATA ANALYSIS}

The values presented are means of 15 measurements \pm Standard deviation (SD) on fresh weight basis. The null hypothesis, $\mathrm{H}_{0}$, that there is no significant difference between the mean values of the parameters in tomatoes ripened under field ripening and those ripened under ambient temperature was tested against the alternative hypothesis, $\mathrm{H}_{1}$, that the differences are significant. The data were analyzed using a software package, GraphPad QuickCalcs Software (from GraphPad Software Inc. USA) by employing the use of student's t-test. The differences between the mean values and the corresponding P-values were computed as shown in the tables.

\section{RESULTS}

Table 1 shows the variations of percent total solids of the tomato fruits of the two cultivars, Ibadan-local and Roma, with ripening stages under different ripening conditions. In both cultivars, the percent "total solids" is highest in the pink stage and lowest at fully-red stage of tomatoes under field ripening. On the contrary, the lowest and highest percent total solids are observed at turnings and fully-red stages, respectively in tomatoes ripened under ambient temperature. The mean differences in percent total solids between tomato fruits ripened on the parent plants and those ripened under ambient temperature range between $-3.64 \%$ and $-0.06 \%$ (negative signs indicate higher value for ambient temperature ripening condition) for Ibadanlocal cultivar and between $-3.03 \%$ and $0.20 \%$ for ripening under ambient temperature. These differences between the two conditions of ripening are significant $(\mathrm{P}<0.05$ at the breaker stage of Ibadan-Local cultivar and $\mathrm{P}<0.01$ for other stages in the two varieties), with the differences much higher at the pink to fully-red stages in tomatoes ripened under the ambient temperature.

The variations in the $\mathrm{pH}$ of tomato fruits with ripening stages are shown in Table 2. The $\mathrm{pH}$ changes in an irregular trough-crest manner. The least and highest $\mathrm{pH}$ values were observed at the fully-red and breaker stages of tomatoes (in both cultivars) ripened in the field but this is not the case for the ambient temperature condition. The $\mathrm{pH}$ differences between the two ripening methods ranged from -0.38 to 0.27 and from -0.35 to 0.10 for Ibadan-local and Roma cultivars, respectively. These differences are significant $(\mathrm{P}<0.05$ at the breaker stage of Ibadan-Local cultivar and at the light-red 
stage of Roma cultivar and $\mathrm{P}<0.01$ for other stages in the two varieties) with exceptions at light-red stage of Ibadan-local cultivar and breaker stage of Roma cultivar.

The highest titratable acidity (as citric acid) (shown in Table 3) of tomato fruits was observed at the pink stage of ambient temperature ripening for Ibadan local variety, and at the pink and light-red stages of ambient temperature ripening for Roma type. The mean differences between the two methods of ripening range from $-0.13 \%$ to $0.10 \%$ and from $-0.11 \%$ to $0.22 \%$ in Ibadan-local and Roma cultivars, respectively. These differences are also significant $(\mathrm{P}<0.05$ at the breaker stage of Roma cultivar and $\mathrm{P}<0.01$ for other stages in the two varieties) with exceptions at fully-red stage of the two tomato varieties.

Table 4 indicates the reducing sugar concentrations of the tomato fruits under the conditions of study with respect to the ripening stages. Reducing sugar concentrations observed at the fully-red stage in both cultivars under field ripening are low while the lowest values observed in tomatoes ripened under ambient temperature are at the turnings and pink stages of Ibadan-local and Roma cultivars, respectively. The mean differences in the reducing sugars between the ripening methods vary between 1.36 and $7.49 \mathrm{mg} / \mathrm{kg}$ fresh weight in Ibadan-local cultivars while the range in Roma cultivar is from -5.88 to $6.83 \mathrm{mg} / \mathrm{kg}$ fresh weight and these are highly significant $(\mathrm{P}<0.01)$ at all ripening stages.

Table 5 shows the concentrations of lycopene in tomato fruits under the two methods of ripening. The lycopene concentration increases from breaker stage to light-red stage in the two cultivars and under both conditions of ripening and decreases on reaching the fully-red stage. The mean differences in the lycopene concentrations between the ripening methods are in the range -0.40 to 18.16 and -2.24 to $26.62 \mathrm{mg} /$ $100 \mathrm{~g}$ fresh weight in Ibadan-local and Roma cultivars, respectively. These are highly significant at the breaker stage of Roma cultivar $(\mathrm{P}<0.05)$ and at all other stages of the two varieties $(\mathrm{P}<0.01)$.

The $\beta$-carotene contents of tomato fruits are shown in Table 6 . These (in both varieties) are relatively higher in the tomatoes ripened in the field than those ripened at ambient temperature. The concentrations of $\beta$-carotene increase as tomato fruits ripened, and the $\beta$-carotene concentrations reach the maximum at the fully-red stage for both varieties, ripened in the field, whereas at ambient temperature, this trend was not observed. Mean differences in $\beta$-carotene concentrations of the tomato fruits between field and ambient temperature ripening methods are in the range 0.24 to 1.955 and 0.239 to $2.375 \mathrm{mg} / 100 \mathrm{~g}$ fresh weight for Ibadan-local and Roma cultivars respectively and these are highly significant $(\mathrm{P}<0.01)$ at all the ripening stages in both tomato cultivars. 


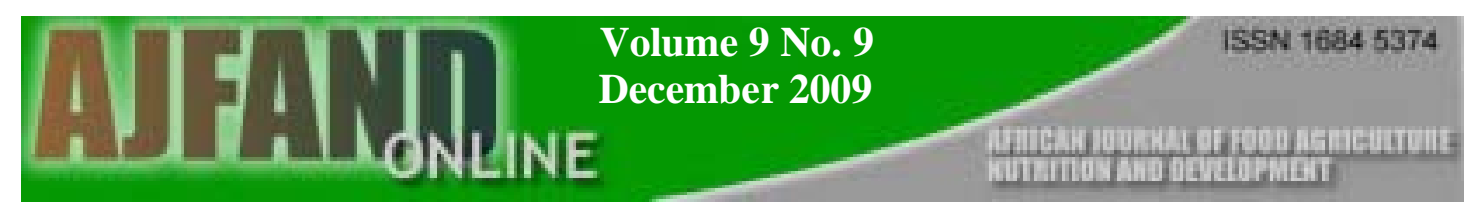

\section{DISCUSSION}

It can be inferred that the percent total solids is higher in the tomatoes (both Ibadanlocal and Roma-type) ripened at ambient temperature than those ripened in the field, suggesting the higher contents of organic matter, minerals and crude fibres in the former as previously reported [4]. This justifies the commercial motive of the ambient temperature ripening method because tomatoes ripening under this condition tolerate rough handling and hold the longest in storage, shipping, and on the supermarket shelf. In the industry, this is referred to as having a low shrinkage rate. The low $\mathrm{pH}$ values obtained at all the ripening stages of tomato (Ibadan-local) ripened in the field and at the ambient temperature suggest high acidity with a very good correlated relationship with total flavour of the fruits which agrees as previously reported [1]. It is probable that those tomatoes fully ripened under field ripening will be sweeter than those ripened at ambient temperature since sweetness correlates with high acidity (low $\mathrm{pH}$ ). No simple trend in the titratable acidity was observed as previously reported [4]. In relation to the titratable acidity (measured as citric acid) in the two tomato varieties ripened under the two different methods, no significant difference was observed at the fully-red stage at which tomatoes are popularly consumed. Owing to high reducing sugar contents of Ibadan-local cultivar, tomatoes ripened in the field could be sweeter with higher degree of sourness and overall flavour intensity than those ripened at the ambient temperature. This result is in agreement with the previous reports, which suggest that for best flavour, high sugars and relatively high acids are required [15, 16]. High acids and low sugars will produce a tart tomato; high sugars and low acids result in a lard taste and low sugars with low acids give a tasteless, insipid tomato. The 'off- flavour' character found in tomatoes of certain cultivars when picked green and ripened off the plant appears to be related to higher concentration of some volatiles, especially 2-methyl-1-butanal with a flavour threshold concentration of 0.1 to $1 \mathrm{ppm}$ [17]. The $\mathrm{pH}$, titratable acidity, total solid and reducing sugar all play a key role in determining the peculiar sensory profile of tomatoes [18].

In relation to the international variations in breast cancer rate and the changes in breast cancer incidence, it has been hypothesized that diet is one of the factors that influence risk [19]. Intake of vegetable and fruits appears to lower breast cancer risk, atherosclerosis, and colon carcinogenesis among other disease conditions and risks. This effect may be related, in part, to the presence of lycopene, $\beta$-carotene, lutein, zeaxanthin and other carotenoids in vegetables and fruits [19-24]. The lycopene content of tomatoes under study increases from the breaker stage and reaches maximum at the light-red stage from where it falls in the fully-red stage. These values are in the range of previously reported values from the UV/ visible spectrophotometric, HPLC and Raman spectroscopic methods [25-29]. The trend is contrary to what has been reported for cherry tomato, generally considered similar but not identical to the wild precursor of the domestic tomato [29]. They are often sweeter than standard tomatoes. The fall of the lycopene content could be attributed to the higher $\beta$-carotene contents in the fully-red stage due to the conversion of lycopene to $\beta$-carotene as depicted in the scheme of reaction (Fig. 1).

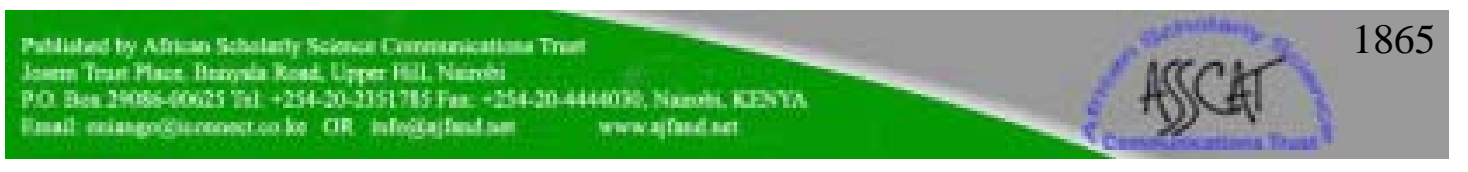


The mean differences in the lycopene contents of the two tomatoes varieties ripened under the two techniques are highly significant. Since the tomato fruits are popularly consumed at the pink to fully-red stages, it could be concluded that the tomatoes ripened in the field were of much higher health benefits (owing to the antioxidant benefits of lycopene) than those ripened under ambient temperature except at the pink stage of the Roma cultivar. The $\beta$-carotene contents of the tomatoes (both varieties) are relatively higher in the tomatoes ripened in the field than those ripened at ambient temperature. The concentrations of $\beta$-carotene increase as tomato fruits ripened with the maximum concentrations at the fully- red stage for both varieties ripened in the field, whereas at ambient temperature, this trend was not observed. The abnormal accumulation of the $\beta$-carotene must be due to its formation from lycopene as shown in Fig 1.

If the claim that the average daily recommendation of lycopene in the Canadian diet is $25.2 \mathrm{mg}$ by estimation [30], such may be obtained by consuming up to $69.2 \mathrm{~g}$ and $58.3 \mathrm{~g}$ of the tomatoes of Ibadan-Local and Roma-types, respectively at light-red stage of tomato ripening on daily basis. Consuming $135.6 \mathrm{~g}$ and $104.7 \mathrm{~g}$ of tomatoes of Ibadan-local cultivars at fully-red and pink stages, respectively as well as $129.9 \mathrm{~g}$ and $110.2 \mathrm{~g}$ of tomatoes of Roma cultivars at fully-red and pink stages, respectively could also produce the same result. However, to achieve this from the consumption of tomatoes ripened under ambient temperature, higher quantities (nearly twice the quantity at light-red stage in Ibadan-local cultivar and three times the quantity at lightred stage of Roma-cultivar of tomatoes allowed to 'self-ripen' on the parent plants) are to be consumed. 

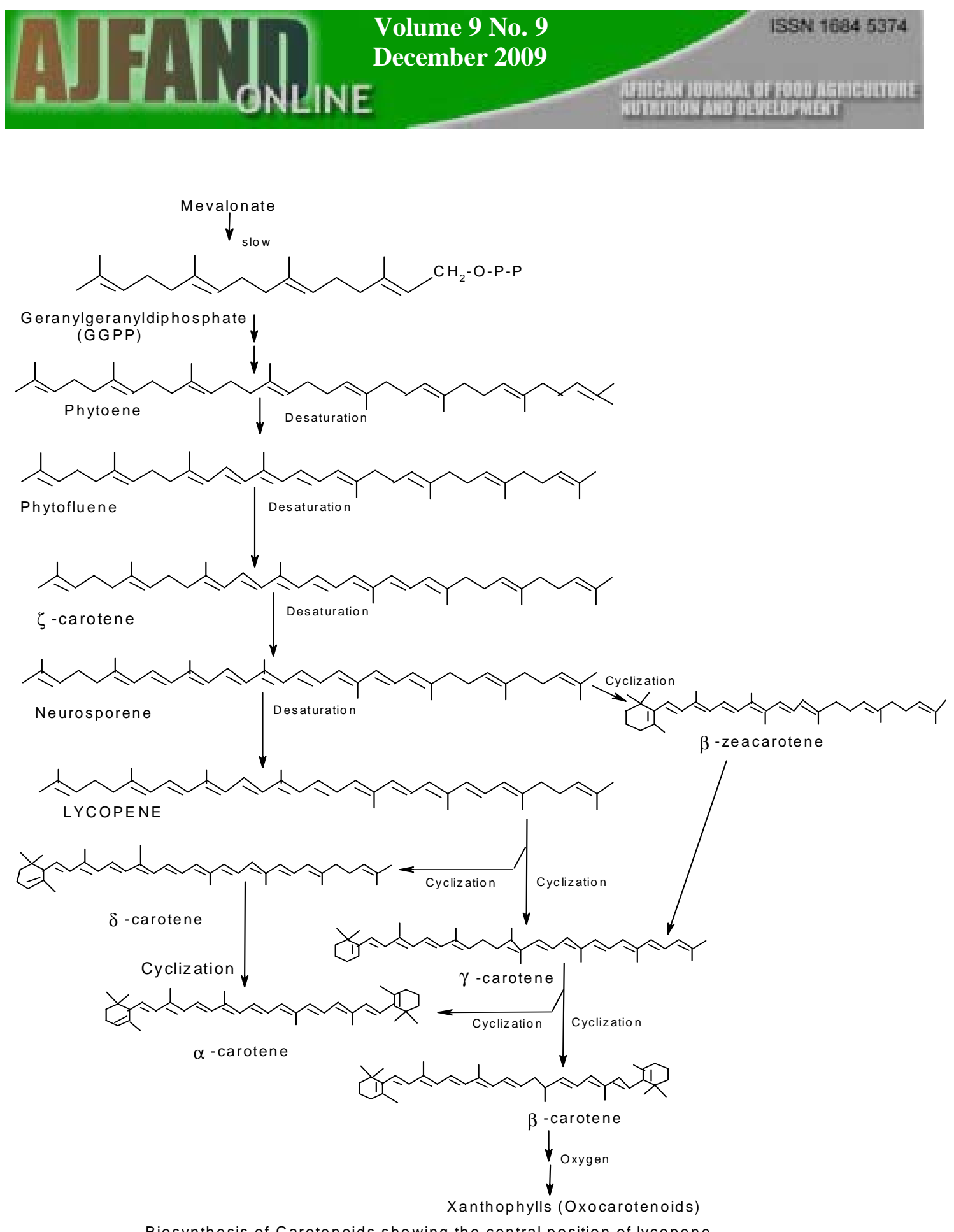

Biosynthesis of Carotenoids showing the central position of lycopene

(Scheme 1)

Figure 1: Biosnythesis of Carotenoids in the mevalonate pathway 


\section{CONCLUSION}

Based on the outcome of this study, it may be concluded that the tomatoes allowed to 'self-ripen' on the parent plant may be of higher quality in terms of sweetness which appeases customers and are better sources of antioxidants than those ripened at ambient temperature. It is, therefore, suggested to the public that health should not be compromised for wealth.

\section{ACKNOWLEDGEMENT}

We are indebted to the Board of Trustees of the Stephen Oluwole Awokoya Foundation for Science Education, Ikeja, Lagos, Nigeria and German Academic Exchange Services (DAAD), Federal Republic of Germany for the postgraduate award and research fellowship awarded to the corresponding author to undertake his research study at University of Ibadan, Nigeria and University of Bonn, Germany, respectively. 


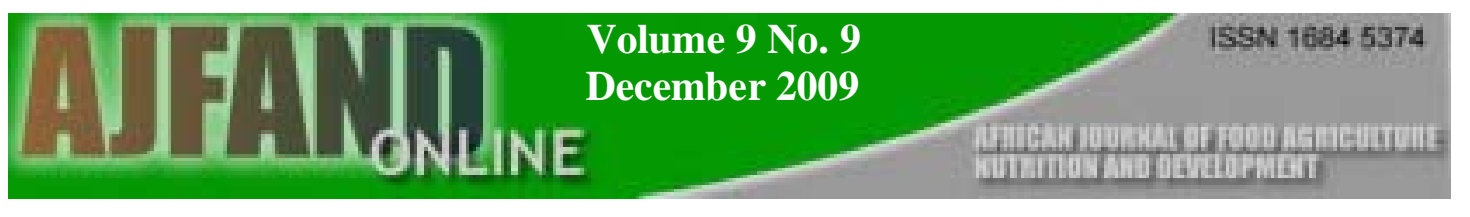

\section{Table 1: Changes in percentage total solids (mean \pm SD) of tomato fruits of different cultivars at different ripening stages under different ripening conditions}

Ripening Ibadan- Local Cultivar

Stages

Breaker

$$
5.80 \pm 0.01
$$

$5.84 \pm 0.01$

$5.53 \pm 0.01$

$5.33 \pm 0.02$

$(0.0363)^{\mathrm{c}}$

$$
-0.06
$$

Turnings

$4.27 \pm 0.01$

$4.33 \pm 0.01$

$4.22 \pm 0.01$

$3.96 \pm 0.01$

$(0.0090)^{\mathrm{b}}$

$(0.0001)^{\mathrm{b}}$

$$
-0.18
$$

Pink

$$
5.91 \pm 0.02
$$

$6.09 \pm 0.02$

$5.86 \pm 0.01$

$6.02 \pm 0.01$

(0.0001)

$(0.0006)^{\mathrm{b}}$

$$
-2.48
$$

Light-Red

$6.82 \pm 0.02$

$$
4.34 \pm 0.01
$$

$6.67 \pm 0.01$

$(0.0001)$

$$
-3.64
$$

Fully-red

a This indicates the mean values of tomato fruits at field ripening minus the means values of those at ambient temperature ripening. Negative values indicate higher mean values for tomato fruits at ambient temperature ripening. P-values are in parentheses.

${ }^{\mathrm{b}}$ Significant at $\mathrm{P}<0.01$

${ }^{\mathrm{c}}$ Significant at $\mathrm{P}<0.05$ 
Table 2: Changes in $\mathrm{pH}($ mean $\pm \mathrm{SD}$ ) of tomato fruits of different cultivars at different ripening stages under different ripening conditions

\begin{tabular}{|c|c|c|c|c|c|c|}
\hline \multirow{3}{*}{$\begin{array}{l}\text { Ripening } \\
\text { Stages }\end{array}$} & & & & & \multicolumn{2}{|c|}{${ }^{\mathrm{a}}$ Mean differences } \\
\hline & \multicolumn{2}{|c|}{ Ibadan- Local Cultivar } & \multicolumn{2}{|c|}{ Roma Cultivar } & \multicolumn{2}{|c|}{ between the ripening } \\
\hline & & & & & \multicolumn{2}{|l|}{ methods } \\
\hline & & & & & \multicolumn{2}{|c|}{ (P-values for mean } \\
\hline & & & & & \multicolumn{2}{|l|}{ differences) } \\
\hline & Field & Ripening at & Field & Ripening at & Ibadan- & Roma \\
\hline & Ripening & Ambient & Ripening & Ambient & Local & Cultivar \\
\hline & & Temperature & & Temperature & \multicolumn{2}{|l|}{ Cultivar } \\
\hline & & & & & 0.27 & 0.02 \\
\hline \multirow[t]{2}{*}{ Breaker } & $4.65 \pm 0.06$ & $4.38 \pm 0.00$ & $4.45 \pm 0.08$ & $4.43 \pm 0.01$ & $(0.0131)^{c}$ & $(0.8053)^{d}$ \\
\hline & & & & & -0.17 & -0.15 \\
\hline \multirow[t]{2}{*}{ Turnings } & $4.22 \pm 0.00$ & $4.39 \pm 0.01$ & $4.23 \pm 0.00$ & $4.38 \pm 0.01$ & $(0.0001)^{b}$ & $(0.0001)^{b}$ \\
\hline & & & & & 0.08 & 0.10 \\
\hline \multirow[t]{2}{*}{ Pink } & $4.24 \pm 0.01$ & $4.16 \pm 0.01$ & $4.28 \pm 0.00$ & $4.18 \pm 0.01$ & $(0.0006)^{b}$ & $(0.0010)^{b}$ \\
\hline & & & & & 0.03 & 0.06 \\
\hline \multirow[t]{2}{*}{ Light-Red } & $4.18 \pm 0.03$ & $4.15 \pm 0.02$ & $4.17 \pm 0.02$ & $4.11 \pm 0.01$ & $(0.4418)^{d}$ & $(0.0303)^{c}$ \\
\hline & & & & & -0.38 & -0.35 \\
\hline Fully-red & $4.08 \pm 0.01$ & $4.46 \pm 0.01$ & $3.87 \pm 0.03$ & $4.22 \pm 0.01$ & $(0.0001)^{\mathrm{b}}$ & $(0.0004)^{b}$ \\
\hline
\end{tabular}


Table 3: Changes in percent titratable acidity (as citric acid, mean \pm SD) of tomato fruits of different cultivars at different ripening stages under different ripening conditions

\begin{tabular}{|c|c|c|c|c|c|c|}
\hline \multirow{3}{*}{$\begin{array}{l}\text { Ripening } \\
\text { Stages }\end{array}$} & & & & & \multicolumn{2}{|c|}{${ }^{\mathrm{a}}$ Mean differences } \\
\hline & \multicolumn{2}{|c|}{ Ibadan- Local Cultivar } & \multicolumn{2}{|c|}{ Roma Cultivar } & \multicolumn{2}{|c|}{ between the ripening } \\
\hline & & & & & \multicolumn{2}{|l|}{ methods } \\
\hline & & & & & \multicolumn{2}{|c|}{ (P-values for mean } \\
\hline & & & & & \multicolumn{2}{|l|}{ differences) } \\
\hline & Field & Ripening at & Field & Ripening at & Ibadan- & Roma \\
\hline & Ripening & Ambient & Ripening & Ambient & Local & Cultivar \\
\hline & & Temperature & & Temperature & Cultivar & \\
\hline & & & & & -0.06 & 0.05 \\
\hline Breaker & $0.57 \pm 0.01$ & $0.63 \pm 0.01$ & $0.68 \pm 0.01$ & $0.63 \pm 0.01$ & $(0.0090)^{b}$ & $(0.0488)^{\mathrm{c}}$ \\
\hline & & & & & 0.10 & 0.22 \\
\hline Turnings & $0.61 \pm 0.01$ & $0.51 \pm 0.00$ & $0.73 \pm 0.00$ & $0.51 \pm 0.01$ & $(0.0006)^{b}$ & $(0.0001)^{b}$ \\
\hline & & & & & -0.13 & -0.11 \\
\hline Pink & $0.78 \pm 0.01$ & $0.91 \pm 0.01$ & $0.67 \pm 0.01$ & $0.78 \pm 0.01$ & $(0.0001)^{b}$ & $(0.0011)^{b}$ \\
\hline & & & & & 0.08 & -0.11 \\
\hline Light-Red & $0.76 \pm 0.01$ & $0.68 \pm 0.01$ & $0.67 \pm 0.01$ & $0.78 \pm 0.01$ & $(0.0080)^{\mathrm{b}}$ & $(0.0013)^{b}$ \\
\hline & & & & & 0.03 & 0.02 \\
\hline Fully-red & $0.51 \pm 0.01$ & $0.48 \pm 0.01$ & $0.51 \pm 0.01$ & $0.49 \pm 0.01$ & $(0.1024)^{d}$ & $(0.1318)^{d}$ \\
\hline
\end{tabular}

${ }^{\mathrm{a}, \mathrm{b}, \mathrm{c}, \mathrm{d}}$ Same as in Table 1 and 2 
Table 4: Reducing sugar concentration (g per kg Fresh weight, mean \pm SD) of tomato fruits of different cultivars at different ripening stages under different ripening conditions

Ripening Ibadan- Local Cultivar

Stages

mean differences)

Field Ripening at Field Ripening at Ibadan- Roma

Ripening Ambient Ripening Ambient Local Cultivar

Temperature Temperature Cultivar

$7.49 \quad 6.83$

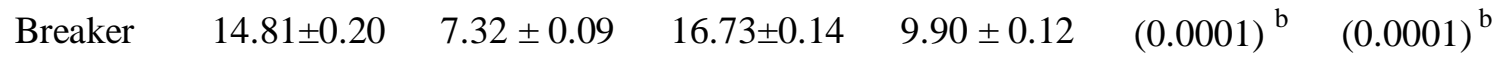

$3.50 \quad 1.86$

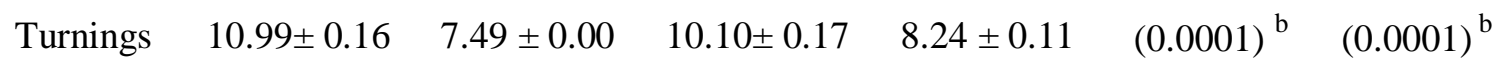

$\begin{array}{lrr}25.88 & 5.71 & -5.8\end{array}$

Pink

$12.92 \pm 0.23 \quad 7.21 \pm 0.08$

$13.31 \pm 0.13$

$19.19 \pm 0.07$

$(0.0001)^{\mathrm{b}}$

$(0.0001)^{\mathrm{b}}$

$6.78-3.04$

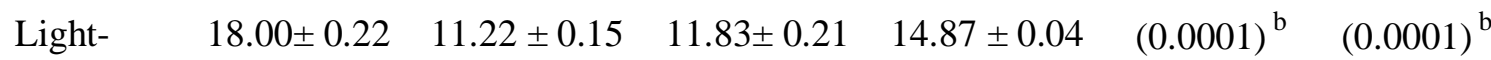

Red

Fully-red $\quad 10.04 \pm 0.13 \quad 8.68 \pm 0.20 \quad 8.24 \pm 0.15 \quad 8.95 \pm 0.09 \quad(0.0007)^{b} \quad(0.0010)^{b}$
1.36
$-0.71$ 
Table 5: Lycopene concentration $(\mathrm{mg}$ per $100 \mathrm{~g}$ Fresh weight, mean $\pm \mathrm{SD})$ of tomato fruits of different cultivars at different ripening stages under different ripening conditions

Ibadan- Local Cultivar

Ripening

Stages

Breaker

$1.49 \pm 0.00$

$1.21 \pm 0.04$

$1.56 \pm 0.07$

$1.75 \pm 0.05$

$(0.0001)^{b}$

$(0.0187)^{\mathrm{c}}$

$-0.40$

$-2.24$

Turnings

$3.15 \pm 0.08$

$3.55 \pm 0.07$

$4.50 \pm 0.01$

$6.74 \pm 0.08$

$(0.0029)^{\mathrm{b}}$

$(0.0001)^{\mathrm{b}}$

15.08

1.82

Pink

$24.07 \pm 0.10$

$8.99 \pm 0.01$

$22.86 \pm 0.02$

$21.04 \pm 0.01$

$(0.0001)^{\mathrm{b}}$

$(0.0001)^{\mathrm{b}}$

18.16

26.62

Light-Red

$36.43 \pm 0.01$

$18.27 \pm 0.05$

4

$43.22 \pm 0.02$

$16.60 \pm 0.10$

(0.0001)

$(0.0001)^{\mathrm{b}}$

4.86

14.18

Fully-red

$18.59 \pm 0.09$

$13.73 \pm 0.10$

$19.40 \pm 0.06$

$5.22 \pm 0.05$

$(0.0001)^{\mathrm{b}} \quad(0.0001)^{\mathrm{b}}$

${ }^{\mathrm{a}, \mathrm{b}, \mathrm{c}}$ Same as in Table 1 
Table 6: $\beta$ - Carotene concentration ( $\mathrm{mg}$ per $100 \mathrm{~g}$ Fresh weight, mean $\pm \mathrm{SD}$ ) of tomato fruits of different cultivars at different ripening stages under different ripening conditions

Ripening Ibadan- Local Cultivar

Stages

$\begin{array}{ll}\text { Field } & \text { Ripening at } \\ \text { Ripening } & \text { Ambient } \\ & \text { Temperature }\end{array}$

Field

Ripening

Ambient

Temperature

0.240

$(0.0001)^{\mathrm{b}}$

0.221

$(0.0001)^{\mathrm{b}}$

0.304

$(0.0001)^{\mathrm{b}}$

1.564

$(0.0001)^{b}$

1.955

$(0.0001)^{\mathrm{b}}$

$(0.0001)^{\mathrm{b}}$

${ }^{\mathrm{a}, \mathrm{b}}$ Same as in Table 1 


\section{REFERENCES}

1. Kader AA, Morris LL, Stevens MA and M Albright- Holton Composition and flavour quality of fresh market tomatoes as influenced by some posthandling procedure. J. Am.Soc Hort. Sci 1978; 103: 6-13.

2. Simpson DJ, Baquar MR, McGlasson WB and TH Lee Changes in Ultrastructure and pigment content during development and senesce of fruits of nor and rin mutant tomatoes. J.Pl. Physiol 1976; 3: 575-587.

3. Crookes PR and D Grierson Infrastructure of tomato fruits ripening and the role of polygalacturonase isoenzymes in cell wall degradation. Pl. Physiol 1983; 72: 1088-1093.

4. Davies JN and GE Hobson The constituents of tomato fruits - The influence of environment, nutrition and genotype. CRC Crit. Rev. Food Sci Nutr 1981; 15: 205-210.

5. Stahl W and $\mathbf{H}$ Sies Lycopene: A biologically important carotenoid for humans? Archiv Biochem Biophys 1996; 336: 1-9.

6. Gerster $\mathbf{H}$ The potential role of Lycopene for human health. J Am Coll. Nutr. 1997; 16: 109-126.

7. Clinton SK Lycopene: Chemistry, biology and implication for human health and disease. Nutr Rev. 1998; 56: 35-31.

8. Rao AV and S Agarwal Role of Lycopene as antioxidant carotenoid in the prevention of chronic diseases. A review. Nutr. Res. 1999; 19: 305-323.

9. Ames BN, Gold LS and WC Willet Causes and prevention of cancer. Proc. Nat. Acad. Sci USA 1995; 92:528-5265.

10. Halliwell B Free radicals, antioxidant and human disease: Curiosity, cause or consequence? Lancet 1994; 344: 721-724.

11. Sanjiv A and AV Rao Tomato lycopene and its role in human health and chronic diseases, CMAJ 2000; 163(6): 739-744.

12. Hobson GE, Adams $\mathbf{P}$ and TJ Dixon Assessing the colour of tomato fruit during ripening, J. Sci. Food Agric. 1983; 34: 286-292.

13. López-Camelo A F and PA Gómez Comparison of color indexes for tomato ripening. Hortic. Bras. 2004; 22(3): 534-537.

14. Pearson D Chemical analysis of Food, Churchill Livingstone, Medical Division of Longman Group Limited, New York: 8th Ed, 1981; 203-206. 
15. DeBruyn JN, Garresten $\mathbf{F}$ and $\mathbf{C}$ Kooistro Variation in taste and chemical composition of the tomato (Lycopersicon esculentum Mill). Euphytica 1971; 20: 214-227.

16. Stevens MA, Kader AA, Albright -Holton M and M Algazin Genotypic variation for flavour and composition in fresh market tomatoes. J. Am. Soc. Hort, Sci 1977; 102: 680-689.

17. Dirinck P, Schreyen E, van Wassenhove F and N Schamp Flavour quality of tomatoes. J. Sci. Food Agric. 1976, 27: 499-508.

18. Pagliarini E, Monteleone $\mathbf{E}$ and $\mathbf{S}$ Ratti Sensory profile of eight tomato cultivars (Lycopersicon esculentum) and its relationship to consumer preference. Ital. J. Food Sci. 2001; 13(3): 285-296.

19. Ching S, Ingram D, Hahnel R, Beilby J and E Rossi Serum Levels of Micronutrients, Antioxidants and Total Antioxidant Status Predict Risk of Breast Cancer in a Case Control Study. J. Nutr. 2002; 132: 303-306.

20. Freudenheim JK, Marshal IR, Vena JE, Laughlin R, Brrasure JR, Swanson MK, Nemato T and S Graham Premenopausal breast cancer risk and intake of vegetable, fruits and related nutrients. J. Natl. Cancer Inst 1996; 88(6): $340-348$.

21. Olabinri MB, Odetola AA and AC Adebamowo Dietary $\beta$-carotene and Vitamin A in relation to breast cancer: A Retrospective study in Nigerian population. Science Focus 2004; 8: 17-20.

22. Malin AS, Qi D, Shu X, Gao Y, Friedmann JM, Jin F and W Zheng Intake of fruits, vegetables and selected micronutrients in relation to the risk of breast cancer. Int J Cancer 2003; 105(3): 413-418.

23. Schnäbele K, Briviba K, Bub A, Roser S, Pool-Zobel BL and $G$ Rechkemmer Effects of carrot and tomato juice consumption on faecal markers relevant to colon carcinogenesis in humans. British Journal of Nutrition 2008; 99(3): 606-613.

24. Frusciante L, Carli P, Ercolano MR, Pernice R, Di Matteo A, Fogliano V and $\mathbf{N}$ Pellegrini Antioxidant nutritional quality of tomato. Mol Nutr Food Res 2007; 51(5): 609-617.

25. Bhoshale P, Ermakov IV, Ermakova MR, Gellermann W and PS Bernstein Resonance Raman quantification of nutritionally important carotenoids in fruits, vegetables, and their juices in comparison to high-pressure liquid chromatography analysis. J. Agric Food Chem. 2004; 52(11): 3281-3285. 
26. Baranska M, Schütze $\mathbf{W}$ and $\mathbf{H}$ Schulz Determination of Lycopene in Tomato Fruits and Related Products: Comparison of FT-Raman, ATR-IR and NIR Spectroscopy. Anal. Chem. 2006; 78: 8456-8461.

27. Choi ST and DJ Huber Influence of aqueous 1-methylcyclopropene concentration, immersion duration, and solution longevity on the postharvest ripening of breaker-turning tomato (Solanum lycopersicum L.) fruit. Postharvest Biol. Technol. 2008; 49(1): 147-154.

28. Raffo A, Leonardi C, Fogliano V, Ambrosino P, Salucci M, Gennaro L, Bugianesi R, Giuffrida F and G Quaglia Nutritional value of cherry tomatoes (Lycopersicon esculentum $\mathrm{Cv}$. Naomi F1) harvested at different ripening stages. J. Agric. Food Chem. 2002; 50(22): 6550-6556.

29. Gautier H, Diakou-Verdin V, Bénard C, Reich M, Buret M, Bourgaud F, Poëssel JL, Caris-Veyrat $\mathbf{C}$ and $M$ Génard How Does Tomato Quality (Sugar, Acid, and Nutritional Quality) Vary with Ripening Stage, Temperature, and Irradiance? J. Agric. Food Chem. 2008; 56 (4): 1241-1250.

30. Rao AV, Zeeshan W and A Sanjiv Lycopene content of tomatoes and tomato products and their contribution to dietary lycopene; Food Res. Int. 1998; 31(10): 737-741. 